Review Article

\title{
You Can't Go Home Again: International Students Adjustment to New Cultural Environments
}

\author{
Prakash Upadhyay \\ Associate Professor of Anthropology \\ Tribhuvan University, Prithvi Narayan Campus, Pokhara \\ Email:prak-socio@ hotmail.com
}

Article History

Received 10 March, 2018; $\quad$ Revised 17 October 2018; $\quad$ Accepted 30 November 2018

\begin{abstract}
Culture shock including its variety of symptoms and outcomes is a completely normal physical and psychological reaction to foreign environments and a part of successful adaptation process--the best and may be even the only means to experience and understand foreign cultures. This article argues that the anxiety and stress related to the adaptation process are shocking but the extent of adjustment does not depend on whether the negative symptoms of culture shock are experienced, but how they are coped with. Adaptation in hosts cultures can be made through different learning processes rather than single learning process that can have positive outcomes in the end, by serving as a hint that something is not right and therefore motivating thinking about how to adjust that can help reduce ethnocentrism and increase acceptance of cultural diversity and appreciation of cultural integrity relating to the challenges of an unfamiliar environment. It is important for spoon-fed theoretically nurtured Nepalese students to grow through this discomfort in order to understand them better and to gain new sensitivities that encourages personal and intercultural competency developments, positive learning experiences leading to increased self-awareness and personal growth in a comparatively developed pragmatic host culture.
\end{abstract}

Keywords: Acculturation, culture shock, ethnocentrism, homesickness, sojourner

(C) 2018 The Author. Published by JRCC, Janapriya Multiple Campus

ISSN 2362-1516

\section{Background}

At a time when the Nepalese government is screening the dream of prosperity to its people, the number of Nepali students travelling for higher education in foreign countries has increased considerably. Nepal Mountain News (2018) notifies that Nepali students have now reached as many as 72 countries and in the year 2018 only, over 60,000 students went abroad for higher study. In an increasingly globalizing world, production of skilled, capable and talented citizen is the modern goal of international students studying abroad which proffer opportunities for personal enrichment, travel, greater chance of graduate school acceptance, job market advantage, and increased awareness of global is sues and cultural differences. Study abroad has both merits and demerits. Embedded with study abroad, culture shock is regarded as a common phenomenon among migrant population which is the special disorientation a person may experience when experiencing an unfamiliar way of life in new country, a move between social environments, or simply travel to another type of life. It is the 
process of initial adjustment to an unfamiliar environment and the psychological construct of adjustment process in emotional, psychological, behavioural, cognitive and psychological aspects. It is that shock or a condition or time of a person in host culture where he/she is searching his or her possessions left in culture of origin e.g. searching same foods, same families, same friends and the same environment.

Culture shock was first named by Kalervo Oberg in 1960 who termed it as an occupational disease or ailment, as intercultural adjustment precipitated by the anxiety that results from losing all our familiar signs and symbols of social intercourse in a non-specific state of uncertainty where the individuals are not certain what is expected of them or what they can expect from the person around them. For Ward et al. (2001) culture shock is the adjustment process of stressful life event that requires a variety of affective, behavioural, and cognitive responses to new environment. Paul (1995) argues that culture shock applies to any situation where an individual is force to adjust to an unfamiliar social system where previous learning process no longer applies.

Guanipa (1998) describes culture shock with a list of negative symptoms and the various stages one may go through when experiencing culture shock. The prevalent problems of culture shock consist of: language barriers, technology gap, acculturation problem, information overload, generation gap, skill-interdependence, formulation of dependency, regress/homesickness, frustrations, alienation and isolation, boredom, responsibility etc. Other symptoms include loneliness, irritability, depression and rigidity. Culture shock results in unexpected and upsetting impression on the mind or feeling, usually one produced by some unwelcome occurrence or perception, by pain, grief, or violent emotion, and tending to occasion lasting depression or loss of equanimity, in weaker sense, a thrill or start of surprise, or of suddenly excited feeling of any kind. Excessive washing of hands, excessive concern over drinking water, foods, dishes, and bedding fear of physical contact with attendants, the absent far-away stare, a feeling of helplessness and a desire for dependence on long-term residents of one's nationality, fits of anger over delays and other minor frustrations, delay and outright refusal to learn the host language, excessive fear of being cheated, robbed, injured, great concern over minor pains, and finally dreadful longing to be back home are the major symptoms of culture shock. Culture shock last for about seven weeks on average and feeling isolated anxiety and worry, reduction in job performance, high energy, and helplessness are the symptoms of culture shock. The psychological and emotional effects of culture shock may be serious physical symptoms including increased amount of illness and injuries, mental trauma, committing suicide, cognitive and behavioural problems.

Culture shock has negative effects on education and work place but there is no precise way to entirely prevent culture shock, as individuals in any society are personally affected by cultural contrasts differently owing to cross-cultural practices of different cultures. Renowned anthropologist Malinowski who is known for his fieldwork suffered from culture shock during his fieldwork in Trobriand. In his diary (1967) he describes symptoms attributable to culture shock-homesickness and depression. McFarland (1999) informs that companies experience expatriate failure and failure to candidate selection due to inability to adapt host cultures. Some companies provide communication preparation for employees to help them 
adapt, other causes of culture shock are rarely addressed/acknowledged by companies or universities. Many students contact University Counseling Services and report feeling alienated because of counselor's lack of knowled ge about their culture.

With increasing globalization, culture shock has been a research topic for European and American anthropologists and psychologists since 30 years before (Eickelmann, 2006). Anthropologists and psychologists have carried out culture shock research on the students of different countries, international workers and migrated people. Research done by them is based on particular class for example Ward et.al (1996) did culture shock experience research on Japanese students in New Zealand. Lysgaard (1955) did research on Norwegian Fulbright grantees in U.S.A. Majority of researches were done on country wise classification of students which is due to students' cultural differences. Amid globalization trend, obsession for Nepalese students for abroad study is escalating but the culture shock impact on them has not been studied circumspectly to help them organize. They find it difficult to adapt themselves to new changed environment, education, situation, job, relationship or perspective requiring role adjustment and a new identity. It starts before the beginning of journey and ends after the complete adaptation in different culture, if failed, students become mentally depressed, some commit suicide, left colleges, move to another country or even return home. Because of its negative effects on students education and workplace, culture shock has become an important research topic, yet little research exists which has investigated differences in its causes and factors. This article investigates various aspects of the causes of culture shock and differing cultural symbolic realities and notions of risk on international students and elaborates the major factors (cross-cultural practices) of cultural shock. The article is pedestal on secondary data congregated from secondary sources- books, journals, and internet sources.

\section{The Clash of Differing Cultural Symbolic Realities and Notions of Risk}

Most research on culture shock originates within the psychological disciplines and focuses on how various groups, such as immigrants, students, charity workers, and anthropologists adapt in new environments. Psychological literature focuses heavily on differing cultural values, with the idea that bothersome values, such as gender roles, conceptions of family, food, and poverty disturb many sojourners. Referring to Hofstede (1997), culture is learned not inherited shaped by parents, relatives, teachers, friends, and the society, anthropologists define culture as a dynamic set of shared attitudes, values, beliefs, goals and practices which characterize a group of individuals. Definition of culture for people is same whether he/she is inside the organization or outside the organization and whether he/she is inside the country or outside the country. There are some key terms like National Culture, International Culture and Organizational. National Culture is a share system of attitude, values, belief, behaviour and norms of people living in a particular country, for example, share system of attitude, values, belief, behaviour and norms of Nepal is the National culture of Nepalese people. Likewise the way of doing things other than their own country can be termed as International Culture. For example cultures of Nepalese are International Culture for foreigners. In the same manner, the way of doing things inside an organization can be termed as Organizational Culture. Organizational Culture includes rules and regulation, responsibility, duty and accountability of any organization. Whether it is national culture, international 
culture or organizational culture, it is nothing more than a share system of attitude, values, belief, behaviour and norms of people living or working inside that particular sector where émigré need to adapt, failure in which may result in culture shock a sudden and disturbing impression on the mind by annoying occurrence/perception.

Acculturation is a major process in culture shock explaining those phenomena which result when groups of individuals having different culture come into continuous first hand contact with subsequent changes in the original culture patterns of either or both groups (Redfield et al. 1936). For Berry et al. (1987) two levels of acculturation (group level and psychological) involve overlapping categories of psychological changes, social and relational changes, cultural changes, physical changes, such as new habitats, and biological changes, such as nutritional and health status changes. Berry (1997) classified psychological acculturation into three groups on the ground that psychological acculturation is a rather undemanding process, and is referred to as behavioural shift, culture learning or social skill acquisition. Accordingly, psychological acculturation involves conflict which seeks resolution and culture shock has its place in this perspective and the close synonym is acculturative stress defined as a generalized physiological and psychological states of the organism, brought by the experience of stressors (risks) in the environment, and which require some reduction (for normal functioning to occur), through a process of coping until some satisfactory adaption to the new situation is achieved. Notions of risk are based upon the shared set of symbols that make up a cultural currency, and risk perception thus can be understood to depend on shared culture, not individual psychology (Douglas and Wildavsky 1982). The problem of risk exists at two levels. Firstly, the unknown (the unfamiliar or the other) is seen as risky, and secondly, clashing conceptions of risk lead to conflict. E.g. Nepalese students abroad may experience anxiety in new socio-cultural environment mainly with language, gestures, customs, signs and symbols that they are used to and when they find that whatever they know suddenly have no meaning or have new meanings. Most upsetting and risky for them may be the loss of social support system (family, friends, classmates, co-workers), and the necessity of starting all over again in an unfamiliar environment

Anderson (1994) has noted that sojourners must cope with obstacles in the new environment like vast difference in values and belief system, differences in communication and interpersonal relationship, and standing out because of physical appearance. Swagler and Jome (2005) distinguished between psychological adjustment and socio-cultural adjustment and as per the psychological adjustment which is the emotional component of intercultural adjustment, and is measured by mental and physical well being and on the other hand sociocultural adjustment is the cognitive and behavioural component. Persons who exhibit good socio-cultural adjustment are able to function well in the new environment. For Berry (1997) psychological adjustment is variable throughout time, and it is determined by social support and personality variables. Socio-cultural adjustment, on the other hand, increases linearly with time and is predicted by cultural knowledge, amount of contact with host culture, and inter group attitudes. Paul (1995) squabble that there are at least six indicators that a culture shock adjustment is taking place. First, familiar cues about how the person is supposed to behave are missing, or the familiar cues now have a different meaning. Second, values the person considered good, desirable, beautiful, and valuable are no longer respected by host. 
Third, the disorientation of culture shock creates emotional state of anxiety, depression, or hostility, ranging from mind unease to host society. Fourth there is a discontent with the new ways and an idealization of the "the way things were". Fifth, recovery skills that used to work before no longer seem to work. Sixth there is a sense that this culture shock discrepancy is permanent and will never go away.

Understanding a new culture is sudden and sometimes unpleasant feeling causing persons to re-evaluate both the new host and their own home culture. Oberg (1960) mentioned six negative aspects of culture shock including (a) Strain resulting from the effort of psychological adaptation, (b) a sense of loss or deprivation referring to the removal of former friends, status, role, and/or possessions, (c) rejection by or rejection of the new culture, (d) confusion in the role definition, role expectations, feeling, and self-identity, (e) unexpected anxiety, disgust, or indigestion regarding cultural differences between the old and new ways, and (f) feeling of helplessness as a result of not coping well in the new environments. Challenges to sense of identity, frustration, anger, withdrawal, depression, exhaustion, and numbness are the major consequences of culture shock. Sicat (2011) reveals that the most common culture shock problem faced by Nepalese students studying in the Philippines is the adjustment to the food and hygiene practices of the Filipinos. Also adjustment with local culture, being homesick and language factor (accent of the English speaking Filipino teachers) are the problems of the Nepalese students creating a feeling of helplessness, frustration and depression as a result of not coping well in the new environment.

As per Swagler and Jome (2005), if those symptoms left unresolved then culture shock can result in premature return to home culture, functional difficulties, and prolonged psychological distress. Culture shock may also result in reverse culture shock mainly in the development of person and international understanding. Reverse culture shock is the repetition of same symptoms in the person after returning to his original culture. Milstein (2005) describes reverse culture shock or re-entry shock, or own culture shock that may take place-returning to one's home culture after growing accustomed to a new one that can produce the same effects as at foreign country. These are the results of psychosomatic and psychological consequences of the readjustment process to the primary culture. The affected person often finds this more astonishing and difficult to deal with than the original culture shock. This phenomenon, the reactions that members of the re-entered culture exhibit toward the re-entrant and the inevitability of the two can be encapsulated in 'You Can't Go Home Again'.

\section{Results and Discussion}

Berry (1997) divided the variables of culture shock into two groups-Environmental Variables and Individual variables. Environmental variables include the host and home cultures, contact with host culture, social support, and duration of residency. Higher the difference between home culture and host culture, harder the adjustment process and vice versa. Greater contact with the host culture smoothes adjustment process but participation and contact must be positive in quality. Culture shock differs from individual to individual and psychological consequences of acculturation process are highly variable, depending on social and personal variables that reside in the society of origin, the society of settlement, and phenomena that both exist prior to, and arise during, the course of acculturation. Anticipatory adjustment, 
personal background, demographics such as age, gender and personality are individual level variables. Black and Mendenhall (1991) divulge that individuals can facilitate the process of cultural adjustment by anticipating and preparing for it. Personality characteristics-willingness to communicate and to establish relationships, tolerance for ambiguity, degree of ethnocentricity, or the degree to which individuals believe their culture is better than other cultures, and willingness to substitute reinforces also facilitate cultural adjustment.

Five Factors Model of Personality Neuroticism, Extraversion, and Openness to experience, Agreeableness, and Conscientiousness influence cultural adjustment (Swagler and Jome, 2005). Neuroticism is the degree to which individuals experience negative emotions and how susceptible they are to stress. Extraversion involves tendencies toward interpersonal interaction, sociability, assertiveness, and warmth. Those who score high on Openness to Experience seek out and enjoy new experiences. Agreeableness are the characteristicssympathy, trust and the ability to work cooperatively with others. Individuals who are high on Conscientiousness tend to be attracted to order, control, and achievement. Low levels of neuroticism and high level of agreeableness, conscientiousness, and acculturation to host culture are correlated with high level of psychological adjustment. High score on extraversion and acculturation to host cultures are correlated with high levels of socio-cultural adjustment. There are other diverse factors related to the sojourner's personality that have a considerable influence on the adjustment process. The motivation to adapt is maybe one of the most important of these factors. This motivation depends largely on the length of stay in the host culture. The longer the stay is expected to be, the higher is the motivation to adapt. Besides motivation there are also the aspects of extraversion and sensitivity that are believed to facilitate adjustment. In contrast to that, authoritarianism, rigidity, and ethnocentrism impede the acculturation process. Other personality factors related to the culture shock process are coping with humor, personal flexibility, and tolerance of ambiguity. Even though some personality factors are generally believed to have a positive influence on the adaptation process, the model of perfect sojourners does not exist.

The culture shock process is only an idealistic one and this cannot be applied to every sojourner in the same way. Why somebody experiences negative effects of culture shock and what determines them, how intense the experience is and whether the individual finds a way out of the crisis cannot be answered by any single model. The degree and length of culture shock vary significantly due to differences in the individual, the cultures involved and the situation of encounter. Furnham and Bochner (1982) distinguish between three categories of conditions that influence the duration and extent of culture shock viz. differences affecting adaptation processes (cultural differences, individual differences, sojourn experience). The ability to cope others culture is affected by knowledge of the culture, language, stereotypes and attitudes towards people of other culture, being able to suspend evaluation of other people's behaviour and understanding the self as a cultural being.

Knowledge about host culture, language, attitudes and behaviour and the length of residence, amount of contact with host nationals, previous experience abroad, and cross-cultural training are commonly considered in relation to cross-cultural adaptation. For cross-cultural adaptation, Nepalese students can increase contact with local culture by reading books, watching local TV programs, talking to people who have extended contact to the host culture 
or directly to host nationals, or by observing the behaviour of members of the other culture. Berry et.al (1987) argues that differences in language of inability to communicate are also predictors of a more stressful adjustment process. But knowledge of local language does not mean that it is essential to speak the local language fluently, but the more of the language is understood, the more of the culture can be understood. Hofstede (1997) states that in order to establish a more fundamental intercultural understanding, it's necessary to learn the host culture's language which is the vehicle of culture transfer. Language fluency bears an easy relationship to socio-cultural adjustment related directly to increased interaction with host nationals and hence the decrease in socio-cultural adjustment problems. Expectations also play an important role in the adaptation process. Realistic expectations are believed to facilitate adjustment, while overly optimistic expectations are likely to result psychological adaptation problems.

Sojourners go through the adaptation process at different rates- some adapt more quickly than others and a few don't not adapt at all. There are many reasons more closely related to the host environment, some countries and organizations are easier to fit to than others e.g. South Asian cultures are more similar to Nepalese students hence they can adjust easily there compared to European. This refers to the concept of cultural distance accounting for the adjustment problems. Students' social networks have a strong influence as well. Having friends who are members of the host society is positively related to the attitude towards the host culture and the speed and degree of cross-cultural adaptation. Personal informal orientation may be more effective than institutionally sponsored assistance.

There may be different solutions for culture shock but it does mean that it works for everyone. Whatever the effectiveness of such solutions e.g. a) effective international human resource management, appropriate émigré recruitment policies (establishing skills/knowledge profile, planning/implementing selection procedures, training/monitoring overseas performance, b) émigré qualification profile (understanding ethnocentrism, intercultural experience, cognitive/behavioral flex, general/ specific intercultural knowledge, adequate behaviour/interpersonal skills, avoiding dual career), may help in reducing culture shock. Didactic host culture sharing training and practical assistance may be supportive. For Nepalese students it may be necessary to congregate intercultural knowledge about the new culture they are going to immerse in viz. about host food, cuisine, shopping, festivals and rituals, dress codes, forms of address and greetings, local language, gestures and body language, attitudes towards smoking, alcohol, gift-giving and neighborliness, daily schedules, political system and organization. Culture's specific beliefs about various aspects of life influence many unwritten rules, relationship to time, personal space and eye contact, gender roles and family life, social classes and ethnic groups, attitudes towards rules, authority, and seniority, work ethic and behavior in the workplace hence it is necessary to develop intercultural skills. Students should be able to interact with the people from new culture without automatically falling back on their own cultural assumptions - even if this means adopting an outlook that they may not share. No matter how much they learn about intercultural communication, it can be never assumed that they can actually reduce a culture to the models, tips, and guidelines meant to support strangers. It's always more complicated because any national culture is not necessarily homogeneous. It is not uniform throughout, 
and culture may not be the same everywhere in the country. There might be sub-cultures differing due to strong regional or religious influences, or due to immigrants mixing the two cultures they navigate daily.

\section{Significance of Culture Shock}

It is myth that experiencing culture shock is a weakness or negative indication of future international success. Culture shock in all its diverse forms is completely normal and is part of a successful process of adaptation. The anxiety and stress related to the adaptation process are not bad in and of themselves. The extent of adjustment does not depend on whether the negative symptoms of culture shock are experienced, but how they are coped with. In fact, they can have positive outcomes in the end, by serving as a hint that something is not right and therefore motivating thinking about how to adjust (Guirdham, 1999). Culture shock experience helps reduce ethnocentrism and increase acceptance of cultural diversity and appreciation of cultural integrity. It is important for students to grow through this discomfort in order to understand them better and to gain new sensitivities. Although culture shock may bring some challenges, it is also a process which encourages personal and intercultural competency developments and serve as an indicator to explore about the foreign as well as the own culture. Study among Canadian expatriates in Africa showed that those who experienced culture shock were most effective and were able to adapt more effectively later on (Guirdham, 1999).

\section{Conclusion}

As a process of intercultural adjustment resulting in a positive learning experience leading to increased self-awareness and personal growth, culture shock in all its diverse forms is completely normal and is part of a successful process of adaptation. There is strong positive relationship between culture shock and social responsibility, immigration policy, politics, mentality, educational infrastructure, educational system, lack of job and repetition of regular activities in foreign country. Cross-cultural perspectives, differences in the culture of origin and host culture practices, lack of education about host culture, environment, interpersonal communication etc may create culture shock. Acceptance of available alternatives in the host culture is the temporary solution of culture shock. Host country's student oriented political situation, immigration policy, education system, and increase in job availability, positive change in mentality and reduction in social responsibility may cause reduction in culture shock. Repetition of regular activities and observation and experiences has strong positive relationship with culture shock and this signifies that adaptation in the culture of hosts can be made through different learning processes rather than single learning process.

Amid the rising trend of going abroad in the name of higher education, culture change is a common occurrence, a psychological phenomenon and part of a learning process acculturation where students want to adapt them self in different culture applied to any new situation, job, relationship or perspective requiring a role adjustment and a new identity. Though culture shock has many negative effects on both students education and work place but there is no permanent way to entirely prevent culture shock, as individuals in any society are personally affected by cultural contrasts differently owing to cross-cultural practices of different cultures. As a consequence of culture shock in foreign culture, reverse culture shock 
or re-entry shock, or own culture shock is encapsulated in 'You Can't Go Home Again'. Students who spend utmost time in one culture and shift to another then visibly new culture is formed -Third or Hybrid Culture- students having this culture neither completely adapt in host culture nor in origin culture. But few defence measures may be vital. Most of the Nepalese and developing countries students have two aims to be in foreign country--to continue their higher study and to stay there for a long time and earn money which is impacted by availability of job, immigration policy, social responsibility and host politics. Developing countries students socialized in theoretically spoon-fed education system find it problematic to adjust with student oriented practical education system of hosts thus considering host countries educational system and educational infrastructure unique and different in various aspects. Theoretical education creates more hypothetical images about host culture and its education system which results in high differences between host culture and culture of origin. This may be the reason that Nepalese and developing countries students may consider lack of job, immigration policy, social responsibility and politics as strong factors causing them culture shock in host country. Hence, cultural education of host country must be provided to the students while still at home. Movies, documentaries, seminars and orientations may be helpful. Abroad study is a good venture but the most important thing is that students should return home after completing their studies. Though there is a tendency among Nepalese students not to return after completing their studies, they should not forget that their country needs them for its prosperity. Nepal needs the knowledge of the international graduates, and there are ample prospects for them in their homeland.

Acknowledgement: I am exceptionally grateful to Prof. Dr. Vikash K.C. for his untiring, plentiful and pragmatic support and constructive academic facilitation on my research works. I am thankful to him for his productive encouragement and relentless support to enhance my occupational and academic career. This research work is a venture solely based on secondary data.

\section{References}

Anderson, L. E. (1994). A new look at an old construct cross-cultural adaptation. International Journal of Intercultural Relationship (18):293-328.

Berry, J.W., Kim U., Minde T., \& Mok, D. (1987). Comparative studies of acculturative stress. International Migration Review 21(3): 492.

Berry, J.W. (1997). Immigration, acculturation and adaptation. Applied Psychology: An International Review (46):5-68.

Black, J.S., and Mendenhall, M. (1991). The U-Curve adjustment hypothesis revisited: A review and theoretical framework. Journal of International Business Studies (22):225-247.

Bochner, S. (2006). Sojourners. In D.L. Sam \& J.W. Berry (Eds.), The Cambridge Handbook of Acculturation Psychology (4):181-197. 
Douglas and Wildavsky, A. (1982). Risk and Culture: An Essay on the Selection of Technical and Environmental Dangers. Berkley: University of California Press.

Eickelmann, C. (2006). Studying Abroad and Culture Shock. The international education site, www.edweb.sdsu.edu/people.

Guanipa, C. (1998). Culture Shock. San Diego State University. Retrieved 3 May 2011 from http://edweb.sdsu.edu/people/CGuanipa/cultshok.htm.

Guirdham, M. (1999). Communicating Across Cultures. Copenhagen Publishers.

Hofstede, G. H. (1997). Culture and Organization Software of the Mind. New York.

Lysgaard, S. (1955). Adjustment in foreign society: Norwegian Fulbright grantees visiting the United States. Acta Psychologia (11): 189-190.

Malinowski, B. (1967). A Diary in the Strict Sense of the Term. London: Routledge.

McFarland, J. (1999). Culture Shock. European Educational Research Proceedings. Lathi, Finland.

Mendenhall, M.E., Kuhlmann, M.T., Stahl, G.K., Osland, J.S.1. (2002). Employee Development and Expatriate Assignments. Oxford; 155-183.

Milstein, T. (2005). Transformation abroad Sojourning and the perceived enhancement of self efficacy. International Journal of Intercultural Relations (29):217-238.

Nepal Mountain News (2018). Over 60,000 Students Going Abroad for Higher Study this Year Alone. https://www.nepalmountainnews.com/over-60000-students-goingabroad-for-higher-study-this-year-alone/. June 30, 2018.

Oberg, Kalervo (1960). Culture shock adjustment to new cultural environments. Radical Anthropology (7):177-182.

Paul, P. (1995). The Five Stages of Culture Shock critical incident around the World. Paul Pederson, Greenwood Publishing Group.

Redfield, R., Linton, R., \& Herskovits, M.J. (1936). A memorandum for the study of acculturation. Man A Monthly Record of Anthropological Science (35):145-146.

Sicat, Rodrigo (2011). Foreign student's cultural adjustment and coping strategies. International Conference on Social Science and Humanity, IPEDR (5):338-341.

Swagler, M. A, \& Jome, L. M. (2005). The effects of personality and acculturation on the adjustment of North American sojourners in Taiwan. Journal of Counseling Psychology 52(4):527-536.

Tolman, E.C. (1922). A new formula for behaviourism. Psychological Review (29):45-54. 
Ward, C, Bochner, S and Furnham, A. (2001). The Psychology of Culture Shock. East Sussex: Routledge.

Ward, C. A. Bhagat R., Landis D. (1996). Handbook of Intercultural Training. London, Thousand Oaks. 